\title{
The Research on Piano Teaching in Universities Based on Curriculum Reform
}

\author{
Zhengchang Zhou ${ }^{1, \text { a }}$ \\ ${ }^{1}$ Music and Dance Institute of Qujing Normal College \\ hunter2011@foxmail.com
}

Keywords: Curriculum Reform, Colleges and Universities, Piano Teaching

\begin{abstract}
The new century, China ushered the largest and the most difficult music curriculum reform of basic education in the history. In this paper, under the background of basic education music curriculum reform, we study the piano teaching situation in Normal University and propose that we should implement music curriculum reform in Normal University as soon as possible to further advance Piano Teaching comprehensive, in-depth reform and to promote the further development of piano pedagogy.
\end{abstract}

\section{Introduction}

The new century, China ushered in the history of the largest and greatest efforts, but also the most difficult music curriculum reform of basic education. This wave of reform, effectively promoting the process of art education, and strive to achieve a historic transformation of the basic education curriculum from discipline-based, knowledge-based development to pay attention to each student, but also for Music Education presented unprecedented challenges. As an important part of the Teachers' music teacher, piano teaching how the status quo; how to adapt to the degree of basic education curriculum reform; in elementary education music curriculum reform, higher teacher education on how to cultivate understand the theory, there are skills, organized, able to teach energy music teachers counseling personnel and other issues is the daunting task facing piano teacher. Therefore, this article intends to Piano Teaching study the current situation in order to provide a theoretical basis and reference for Piano Teaching Reform [1].

\section{The Implementation Background of Curriculum Reform}

In 1999 China's new round of basic education curriculum reform was officially launched in January 2000 to June through the declaration, assessment, established for each curriculum standards development groups. From July 2000 to February 2001, each research group on the basis of case studies on the formation of the first draft curriculum standards. March of Basic Education, Ministry of Education to educate the majority of workers and experts consulted in nine regions, each curriculum standard for further modification. July the Ministry of Education promulgated the "Basic Education Curriculum Reform (Trial)", thus, primary and secondary schools compulsory national curriculum standards cover 18 subjects developed to complete, from September 1 to enter the basic education curriculum reform experimental zone. After the national basic education work conference, basic education curriculum reform blowing, basic education curriculum reform experimental work in the country 27 provinces, autonomous regions and municipalities of 38 experimental zones in full swing [2].

Implementation of the new high school curriculum reform is to adapt to technological development and the social cultural changes needed to improve the quality of education the objective needs of high school, is the development trend of international education reform, to promote quality education is an inevitable requirement. With the deepening reform of the new round of the high school curriculum, basic education curriculum existing problems and shortcomings of obvious each day, mainly as follows: school education too much emphasis on knowledge transfer, ignoring the students' social, values, and creativity; course content "complex, difficult, partial, old," and too much 
emphasis on book knowledge, out of the student experience; current curriculum in core subject knowledge, too much emphasis on discipline-based, emphasizing the independence of the different disciplines, too many subjects, ignoring the science Contact between art and morality, ignoring the integration and correlation between disciplines; students learn too much emphasis on receiving learning, rote, mechanical training, teacher-centered teaching, classroom-centered, textbook- center, no respect for the students, the lack of independent inquiry and cooperative learning opportunities; too much emphasis on educational evaluation concept evaluation and selection functions do not neglect the promotion of learner development and evaluation of improved educational function; curriculum too focused on management, emphasizing unity, neglect the role of local and school curriculum management and development of the national curriculum and so dominate the world. To reverse this situation, the depth of reform in terms of new curriculum standards made geography teaching purposes, course objectives, teaching content, teaching concepts, teaching methods and evaluation system to improve geography teaching and teaching effectiveness of teachers to meet the growing economy social talent requirements.

\section{The Situation of Piano Teaching in Normal University}

Currently, under the basic education curriculum reform background music, to seek an effective way of teaching to conform to modern music education reform for the new century foster an innovative spirit and practical ability of music education personnel, Piano has become the key issue of education . Meanwhile, the high level of Piano raise the artistic level of education and science, in turn a positive role in basic music education objectives reflected in the higher level. From the existing situation, the prominent problems of Piano Teaching are mainly manifested in [3]:

First, the training objectives are not clear. Under the existing syllabus, Music Teacher training goal is for the country to train qualified primary and secondary school music teacher, this objective determines Piano Teachers teaching in the teaching content, teaching methods, education and other aspects of the evaluation should be consistent with this. However, the phenomenon that teacher putting too much emphasis on technology is still very serious in the actual teaching. The vast majority of teachers pay attention to the overall quality of students' ability and artistic practice, the blind pursuit of piano skills training, less stressed piano in practice use. So many graduates piano playing a high level, but the face of primary and secondary school textbooks song accompaniment of music could not do the job.

Second, specialization tends are serious. China's current piano education, there are two teaching modes: one is the normal class teaching mode, one is teaching mode Conservatory of Music teaching structure but both are essentially different. Teachers should have a distinctive characteristic, the professional requirements towards more energy, extensive and comprehensive direction. And Normal is different, training objectives Music Academy is to train the cast and crew have a high professional level, teaching focuses on student performance skills and performance ability of the training. But the current situation is a lot of blind imitation of Teachers College of Music professional music institutions, even according to the Academy of Music teaching model students, resulting in Piano Teaching deviates from the actual teacher education.

Third, ignore the basic training. After years of teaching experience I found that many students Teachers little attention to basic training, playing methods are not standardized, they think these things dry and tasteless, often focus on the bomb would be music. And some students are learning piano entrance before the assault a year or a few months, learning is not the system, only to meet the test bomb test track, the track and the actual level of the candidates played a considerable gap, but also to develop some bad habits on learning (such as unskilled read music, play by rote, etc.), for piano training and continuous learning to enter college after potential problems.

Fourth, the adult piano teaching. Teachers Students advantage in piano performance in the learning process of learning objectives clear, rich life experience, good at discovering problems, good at understanding teacher's intentions. But there is also a short time in school and less time practicing, fingers are not flexible, the level of disparities and other adverse conditions. For example, from the 
student's school age, the general in about 18-20 years old, there are older, tend to adult phenomenon, its skeletal ripe hand conditions are not suitable to play the piano, playing skills training effect is far less children, and each person in the study of the piano is not the same adaptability [4].

\section{The Discussion and Recommendations}

The professional piano lessons as an important main course and adjust and expand their teaching contents and curriculum system is bound to become musical education reform an important part to further improve the level of artistic piano teaching, scientific level and the overall quality of teaching and improve the overall quality of students play an important role in the primary. I, as many years engaged in teaching piano music educators, believe that to solve the above-mentioned process of Piano Teaching Problems of development should be based on the needs of music education, innovative music education model, teaching methods and content, and from the following aspects reform and adjustment:

Choose the teaching content. Choice of teaching content to suit the Normal music professional training objectives for the criteria must have their own unique materials. Not like the music as a piano student of professional institutions, systems, massive play etudes and foreign music, but should pay attention to the diversity of materials and typical targeted. Teaching content should be clear and focused. As in the initial stages of multi-use texture with accompaniment tracks, from the texture of the prototype to the deformation texture various accompaniment figurations relatively intensive training, playing well and then for another figure. Teachers from high school music students generally have the professional qualifications and extremely limited study time reality, choose piano teaching materials should have a practical, unit, nationality, fusion characteristics, Deep, from simple to complex , step by step, and can draw categorized grade materials. Tracks should be mainly small and medium sized Chinese and foreign songs, use a small amount of technology, there is a certain degree of difficulty on the performance of Chinese and foreign songs.

Strengthen the basic training. Basic Training is the main content of Piano Lesson. Conventional teaching practice has proved that any novice attention to basic training, basic skills a solid student, later grades are better. Piano teaching, the use and master the correct method of play, playing techniques is the central task of teaching basic skills, is the primary task of the College Music Major Piano Teaching is not the correct method of playing, technical skills and the lack of scientific and physiology motion-based psychological play skills would not have made considerable progress. Thus piano professional needs solid, excellent professional basic skills, high professional music teacher also requires corresponding good technical momentum. Sense: basic skills conducive to reflect better the more "normal characteristics", the more conducive to the development of teacher professional personality. On the contrary, there are no certain technical skills.

To enhance the skills of improvised accompaniment. For a long time, playing Piano Teaching emphasis on skills training, too specialized, this seemingly "high quality" teaching piano teaching has deviated from the purpose of teacher education - primary and secondary schools for music education and training of qualified teachers. Some students have the ability to play high, but not as a simple impromptu song accompaniment, that simply can not be qualified primary and secondary schools of music teaching. Since it is a piano teaching music education in order to train qualified personnel, it should enable students not only have the ability to play the piano, but also in various needs of occasions impromptu piano accompaniment. Accordingly, Music Education, at the same time learning piano skills training, but also to emphasize to students depending on played piano accompaniment and improvisation ability, financial techniques, teaching methods as a whole, for a variety of music genres, performed with piano playing and improvisation Training accompaniment ability [5].

Make clear the career orientation. Professional music teaching in higher normal colleges, piano lessons are very important for students' compulsory basic course. Because of its technical, highly practical features, for a long time, the Higher Teachers College Music Major Piano Teaching is essentially followed the model professional music teaching institutions. However, with the 
continuous improvement of the education system and the continuous development of teacher education, purposes and objectives of Teachers of music education is to create a music education system with Chinese characteristics, service, qualified training for the whole society and middle schools music teacher. Teacher education students not only to learn the piano to play the piano, but also to prepare for the future engaged in basic piano teaching, which requires high teacher student has a good foundation piano, playing the right ideas, to master the basic piano pedagogy at the same time, He wants to know the relevant knowledge pedagogy and psychology. Thus, the College Music students should identify future professional career orientation for the future work better in piano education foundation.

\section{Conclusion}

With the gradual deepening of the basic education music curriculum reform, explore and reform of Piano Teaching has a long way to go. In the reform it is necessary to follow the objective law of piano art teaching and learning, but also to highlight the normal characteristics of teacher education. Therefore, as the piano teaching teachers, they should continue to innovate, update teaching concepts and seek an effective piano teaching mode to adapt to the needs of modern music education reform for the new century to train more high-quality piano education talents.

\section{References}

[1] X.Zhang, Educational reform and development strategy of schools music, J. Central Music Conservatory, 5(2007) 46-47.

[2] C.Li, On piano double major set in colleges and universities, J. Qiqihar University. 11(2006) 26-30.

[3] C.Y.Wang, Knowledge preparation and combined effect before the piano practice, J. Contemporary Ecological Agriculture Social Forum. 12(2009) 56-58.

[4] J.X.Li, I Research on performing art teaching, J. Shenyang Music Conservatory .9(2009) 19-22.

[5] Y.X.Zhang, Research on Piano Teaching, J. Qiqihar University. 4(2007) 129-132. 